Original research article

\title{
Association of depression, anxiety and post-traumatic stress disorder with migraine: Data from Kosovo
}

\author{
Nexhmedin Shala ${ }^{a}$, Shemsedin Dreshaj, ${ }^{b, *}$ \\ a University of Prishtina, Faculty of Medicine, Clinic of Neurology, Prishtina University Clinical Centre, Kosovo \\ ${ }^{\mathrm{b}}$ University of Prishtina, Faculty of Medicine, Clinic of Infectious Diseases, PrishtinaUniversity Clinical Centre, Kosovo
}

\section{A R T I C L E I N F O}

Article history:

Received 30 March 2017

Accepted 7 March 2018

Available online 15 March 2018

Keywords:

Migraine

Depression

Anxiety

PTSD

Kosovo

\begin{abstract}
A B S T R A C T
Introduction: Migraine is ranked as the seventh leading cause of disability worldwide, and it is characterized by a manifestation of combined neurological, gastrointestinal, and autonomic symptoms linked with different provoking factors.

Aim of the study: This study investigates the association between migraine and PTSD, depression and anxiety in the Kosovo population during the post-war period.

Material and methods: 273 war survivors with headache were enrolled in the study and were divided into two groups: 153 individuals with confirmed migraine (the study group) and 120 individuals with non-migraine headaches (control group). All individuals were evaluated using the ICHD-II 2004 diagnostic criteria for migraine, as well as the mini-test for PTSD, MMPI (Minnesota Multiphasic Personality Inventory) for psychological evaluation, PAI (Personality Assessment Inventory) and Hamilton Scale for Depression.

Results: Among migraine patients, depressive disorders were present in $27.5 \%$ of patients, anxiety was found in $60.8 \%$, and PTSD was present in $39.2 \%$. While the prominence of depression was not different between groups, anxiety was significantly more common $(p<0.05)$ in women from the control group. PTSD was significantly more common $(p<0.001)$ in migraine patients overall, whereas the difference in PTSD prevalence between women from the migraine and control groups came close to significance $(p=0.05)$. Females in the migraine group had higher incidences of aura ( $50 \%$ vs. $25.5 \%$ ), whereas the incidence of aura in males in each group was approximately equal ( $9.8 \%$ vs. $7.84 \%$ ).

Conclusion: Based on our data, we can confirm an association between PTSD and migraine in a sample of patients from Kosovo.

๑) 2018 Polish Neurological Society. Published by Elsevier Sp. z o.o. All rights reserved.
\end{abstract}

\footnotetext{
* Corresponding author at: University of Prishtina, Faculty of Medicine, Clinic of Infectious Diseases, University Clinical Centre, Xhorxh Bush n.n. 10000, Prishtina, Kosovo.

E-mail address: shemsedin.dreshaj@uni-pr.edu (S. Dreshaj).

https://doi.org/10.1016/j.pjnns.2018.03.003

0028-3843/@ 2018 Polish Neurological Society. Published by Elsevier Sp. z o.o. All rights reserved.
} 


\section{Introduction}

Migraine is a primary headache disorder characterized by moderate to severe recurrent headaches with manifestations of combined neurological, gastrointestinal, and autonomic symptoms that are linked with different provoking factors. It is more highly prevalent in urban residents and females [1,2]. It is known that migraine is ranked as the seventh leading cause of disability worldwide when it is combined with asthma, anxiety and depression [1]. Because of these stressors, an individual's response is associated with increased anxiety [3,4].

There are studies demonstrating an association between migraine and specific psychiatric disorders in the general population $[4,5]$. Although the association between migraine and depression is the most widely reported, there are also strong associations between migraine and other psychiatric disorders and conditions [6]. Researchers have reported that anxiety disorder, post-traumatic stress disorder (PTSD) and depression are more common in adults with migraine [2,7]. Migraine and PTSD are both more common in women than in men (up to three times higher incidence) [8], indicating that gonadal hormones are likely responsible for the divergence in prevalence rates of migraine and PTSD between the sexes after puberty [9]. Other authors have reported higher incidences of PTSD in females compared to males, and this is linked with higher rates of interpersonal trauma in females, such as physical and sexual abuse [7,10]. Recent data suggest that the probability of a year-long prevalence rate of PTSD is increased in both sexes with episodic migraine; however, a stronger correlation was observed for men $[11,12]$. The age at which a traumatic life event resulting in PTSD occurs seems to have an important influence on PTSD-migraine association, such that when a traumatic event occurs before the age of 13 , the risk of major depression is greater than the risk of PTSD; however, when the traumatic life event occurs after 12 years of age, the risk of PTSD is greater and has a direct influence on disability $[7,13]$. In a multi-center study conducted by Peterlin et al. [7], the impact of headache on participants with PTSD and episodic migraine was higher than in individuals without PTSD. Another study conducted by Sareen at al. [14] reported that anxiety, combined with several community conditions, directly influences both quality of life and disability. To improve quality of life and disability, prophylactic stress management therapies were recommended [15].

Since different stressors such as PTSD and depression have a direct impact on the frequency and gravity of migraine $[7,14]$, and taking into consideration the high prevalence of PTSD among survivors of the Kosovo war (showing the vulnerability of Kosovar population) [16-19], the aim of our study was to determine the influence and association of migraine with PTSD, depression and anxiety among war survivors in the Kosovo population during the post-war period.

\section{Material and methods}

The study was carried out between 2005 and 2008 in the Clinics of Neurology, University Clinical Centre in Prishtina?.

\subsection{Participants}

Participants were sorted into two groups: a study group (153 individuals) and a control group (120 individuals). The study group was a group of patients diagnosed with migraine, whereas the control group was a group of patients complaining of headache but not diagnosed with migraine. The patients in both the study and control groups experienced the war and had histories of headache. The study was approved by the Ethical Committee of the University Clinical Centre and the participants have signed the informed consent.

\subsection{Assessment}

Participants in both the study and control groups were evaluated using the ICHD-II 2004 diagnostic criteria for migraine, as well as the mini-test for PTSD, the MMPI (Minnesota Multiphasic Personality Inventory) for depression evaluation, the PAI (Personality Assessment Inventory) to distinguish between depression and anxiety, and the Hamilton scale for depression and electroencephalography. The study was carried out on the basis of a self-assessment questionnaire about migraine, neurological and psychiatric evaluation. Subjects completed a questionnaire to evaluate migraine symptoms, anxiety, depression, and post-traumatic stress. For both groups, the first part of the instrument consisted of questions related to the 2004 diagnostic criteria for the International Headache Society (IHS) for migraine. The subjects with confirmed migraine underwent a detailed neurological assessment by a neurologist, as well as a psychiatric examination using the structured clinical interview for DSM-IV-R Axis I (Diagnostic and Statistical Manual of Mental Disorders).

\subsection{Statistical analysis}

A Chi-square test was applied to analyze the association between psychological factors and migraine. IBM SPSS software was used.

\section{Results}

During the period between 2005 and 2008, 153 migraine patients (consisting of 126 women and 27 men, ages 11-60) and 120 non-migraine patients (including 72 women and $48 \mathrm{men}$, ages $11-60)$ were enrolled in the study. The majority (68.6\%) of the migraine patients were between 30 and 50 years old. Among the study group, 66 patients (54 women and 12 men) were from rural areas, whereas 87 (72 women and 15 men) were from urban areas. On the other hand, in the control group, 51 patients ( 31 women and 20 men) were from rural areas, while 69 patients (41 women and $28 \mathrm{men}$ ) were from urban areas. A summary of characteristics of patients in the study and control groups is presented in Table 1.

Somnolence and vertigo were found more frequently in migraine patients than in subjects from the control group ( $p<0.001$ and $p<0.05$ respectively), whereas other signs and symptoms, such as transitory diplopia, scintillating scotoma, mydriasis and ataxia appeared only in the migraine patient 
Table 1 - Characteristics of the study and control group.

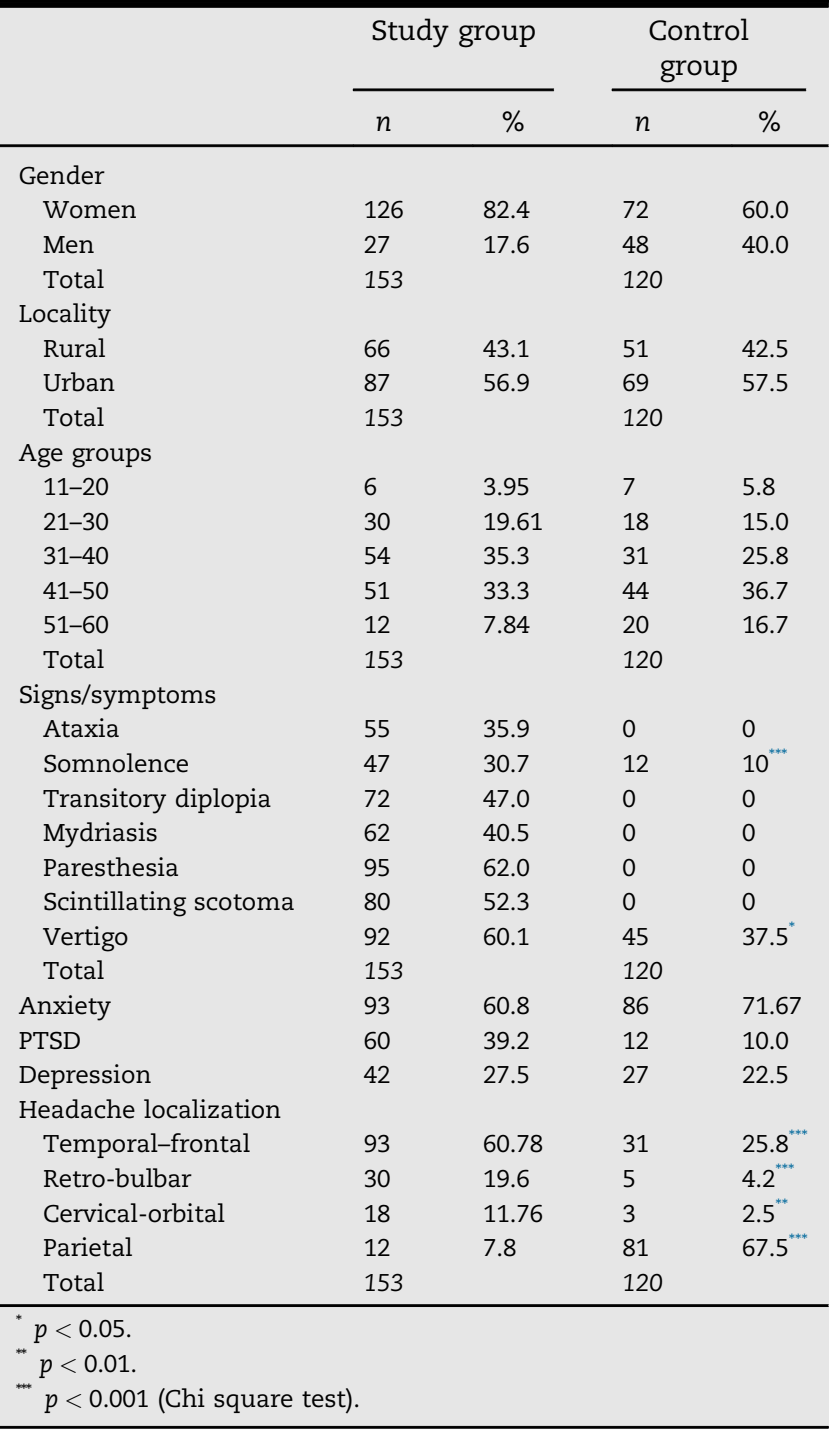

$\%$

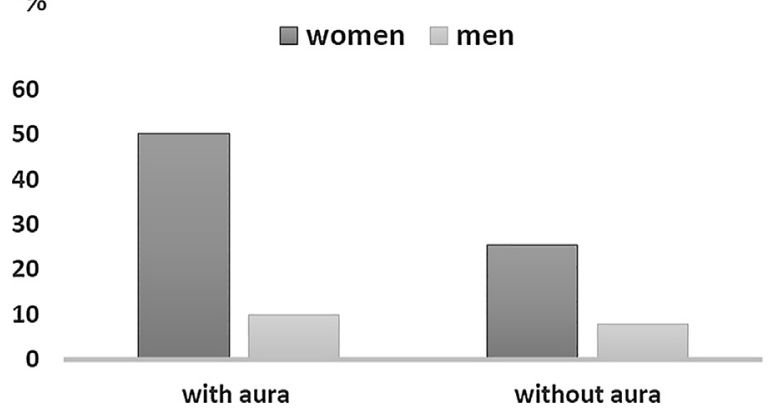

Fig. 1 - Aura among the study group.

group. A significant difference between the study and control groups was seen with regard to vertigo and somnolence $(p<0.001)$ (Chi-square test) (Table 1$)$.

In total, 42 subjects from the study group (27.5\%) had depressive disorders, whereas 27 subjects from the control group exhibited these disorders (22.5\%). Additionally, 93
Table 2 - Depression and anxiety in migraine patients.

\begin{tabular}{lccccc} 
& \multicolumn{2}{c}{ Study group } & & \multicolumn{2}{c}{ Control group } \\
\cline { 2 - 3 } \cline { 5 - 6 } & Women (\%) & Men (\%) & & Women (\%) & Men (\%) \\
\hline Depression & 31 & 11 & & 29 & 12.5 \\
Anxiety & 62 & 56 & & $89^{*}$ & 46 \\
\hline$\chi^{2}, p<0.05$ & (compare to women from the study group). \\
\hline
\end{tabular}

subjects from the study group (60.8\%) had anxiety disorders compared with 86 subjects from the control group $(71.7 \%)$.

Headache was a dominant symptom present in all patients. However, as shown in Table 1, there was a significant difference between migraine and non-migraine patients with regard to the localization of the headache. The dominating headache localizations in migraine patients were the temporal-parietal, retro-bulbar and cervical-orbital regions, whereas the dominating localization in non-migraine patients was the parietal region.

Fig. 1 presents the gender distribution of aura. Based on our data, among the migraine patients, the percentage of women with aura is much higher than the percentage of women without aura ( $50 \%$ vs. $25.5 \%$ ), whereas the difference in aura is very small among men (9.8\% vs. $7.84 \%)$.

Table 2 shows the association between depression and anxiety for the two groups. While there were no prominent differences in the prevalence of depression, anxiety was significantly more common $(p<0.05)$ in women from the control group compared to women from the study group.

Fig. 2 shows the data from the comparison of PTSD prevalence among the study and control groups. PTSD was significantly more common $(p<0.001)$ among the study group compared to the control group. In addition, the difference in PTSD rates between women from the study group and the control group came close to significance $(p=0.05)$.

\section{Discussion}

Population-based studies provide consistent evidence for a positive association between migraine, anxiety disorder, and depression [6]. Anxiety disorders, depression and migraine affect many people, with a prevalence of approximately 10$15 \%$, and all are more likely to affect women [5]. Migraine worldwide spreads episodic headache with wide clinical presentations and is often linked with PTSD [1,2]. Among the subjects with episodic migraine and PTSD, $69 \%$ of symptoms related to PTSD appeared before the onset of severe or frequent headache [11]. It is worth emphasizing that, although migraine is ranked as the seventh leading cause of disability worldwide, it is often found to be comorbid with asthma, anxiety and depression [11].

Our data show that, among migraine patients (153 migraine patients), 6 (3.95\%) are younger than 20 years old, whereas $68.6 \%$ are between 30 and 50 years old, which is similar to the findings of other studies. Among the study group, our data show a higher incidence of aura in women with migraine, whereas the differences were very small for men. Furthermore, similar to other studies [1], in our study, migraine was presented as a disease with wide clinical presentations. 


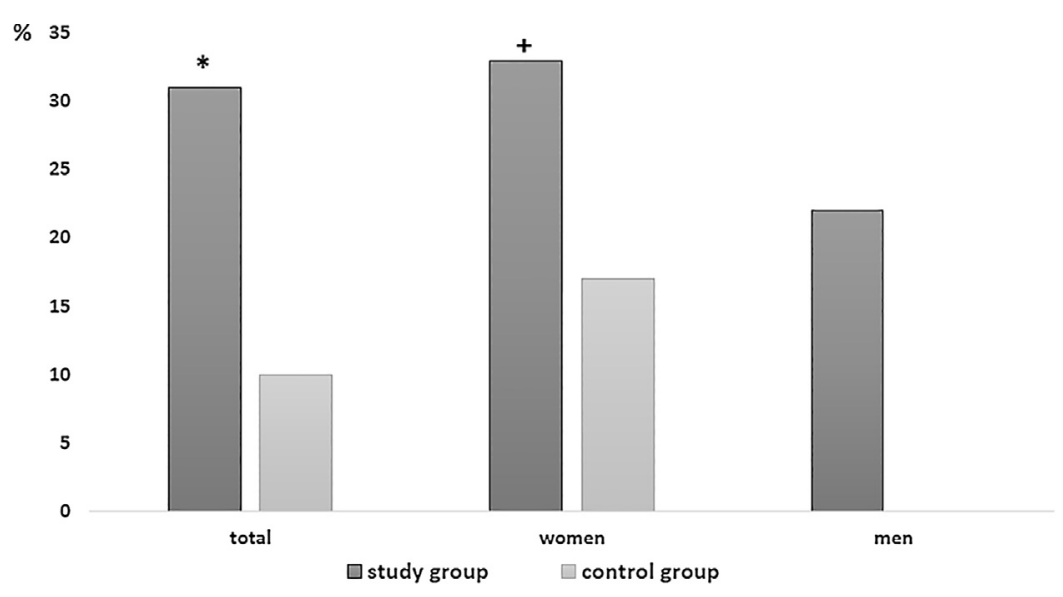

Fig. 2 - The percentage of PTSD in migraine patients and control group. A significant $(p<0.001)$ difference between the study and control group (chi square test). The difference in the percentage of women with PTSD between study and control group was at the border of significance $(p=0.05)$.

Headache as a dominant symptom was present in all patients. In migraine patients, temporal-parietal, retro-bulbar and cervical-orbital headaches were significantly more common, whereas non-migraine patients showed a dominate parietal localization of headache. Vertigo and somnolence were present in both groups; however, they were more common in migraine patients than in the control group $(p<0.001)$. Other signs and symptoms, such as transitory diplopia, scintillating scotoma, mydriasis and ataxia only appeared in the migraine patient group and present parameters that are directly linked with migraine [20].

It is interesting that anxiety was more common $(p<0.05)$ in women from the control group than women in the study group, but depression was equally prevalent. This finding can be attributed to the prevalence of psychological disorders in survivors of the Kosovo war. In this regard, Kashdan et al. [17] reported the association between anxiety and depressive disorders, as well as PTSD among Kosovo war survivors. However, the available data on the psychiatric conditions of Kosovo war survivors is still insufficient $[18,19]$. In this context, it is worth mentioning that the comorbidity of anxiety and depressive disorder is reported to be generally high $[16,21]$.

Regarding PTSD, our data present a significantly higher $(p<0.001)$ prevalence of PTSD among the subjects of the study group compared to control subjects. In addition, the percentage of women with PTSD within the study group was much higher compared with women from the control group $(p=0.05)$. Similar findings were reported in other studies $[11,22]$. With the goal of explaining the etiology and the association between migraine and psychiatric conditions, researchers recommend a multifactorial approach, starting from uni- and bidirectional causal models, combined with environmental, genetic risk factors, and latent brain state models [23]. A multifactorial approach to these patients is recommended, especially for younger patients with depressive symptoms and for those from LMICs [24,25]. Based on these findings, for more successful treatment, doctors who treat migraine patients need to be aware of the potential comorbidity with PTSD [26].

\section{Conclusions}

Based on the obtained data, we can confirm an association between PTSD and migraine in a sample of patients from Kosovo. Our data further confirm that migraineurs should be screened for PTSD and suggest that further research on the association between PTSD and migraine, with a focus on sex differences and treatment implications, is warranted. Since this is one of a limited number of studies carried out in the Kosovar population that survived the war, further investigations to characterize the level of vulnerability are suggested.

\section{Conflict of interest}

None declared.

\section{R E F E R E N C E S}

[1] Vetvik KG, Mac Gregor EA. Sex differences in the epidemiology, clinical features, and pathophysiology of migraine. Lancet Neurol 2017;16(1):76-87.

[2] Woldeamanuel YW, Cowan RP. Migraine affects 1 in 10 people worldwide featuring recent rise: a systematic review and meta-analysis of community-based studies involving 6 million participants. J Neurol Sci 2017;15(372):307-15.

[3] APA (American Psychiatric Association). Posttraumatic stress disorder. Diagnostic and statistical manual of mental disorders. 4th ed., text revision. Washington, DC: American Psychiatric Press Inc; 2000. p. 427-9.

[4] Breslau N, Kessler RC, Chilcoat HD, Schultz LR, Davis GC, Andreski P. Trauma and posttraumatic stress disorder in the community: the 1996 Detroit area survey of trauma. Arch Gen Psychiatry 1998;55:626-32. 
[5] Alonso J, Angermeyer MC, Bernert S, Bruffaerts R, Brugha TS, Bryson H, et al. Prevalence of mental disorders in Europe: results from the European Study of the Epidemiology of Mental Disorders (ESEMeD) project. Acta Psychiatr Scand 2004;420(Suppl.):21-7.

[6] Zwart JA, Dyb G, Hagen K, Oedegaard KJ, Dahl AA, Bovim G, et al. Anxiety and depression associated with headache frequency. Eur J Neurol 2003;10:147-52.

[7] Peterlin BL, Tietjen GE, Brandes JL, Rubin SM, Drexler E, Lidicker JR, et al. Posttraumatic stress disorder in migraine. Headache 2009;49:541-51.

[8] Lipton RB, Scher AI, Kolodner K, Liberman J, Steiner TJ, Stewart WF. Migraine in the United States: epidemiology and patterns of health care use. Neurology 2002;58:885-94.

[9] Macgregor EA, Rosenberg JD, Kurth T. Sex-related differences in epidemiological and clinic-based headache studies. Headache 2011;51(6):843-5.

[10] Butterfield MI, Becker M, Marx CE. Post-traumatic stress disorder in women: current concepts and treatments. Curr Psychiatry Rep 2002;4:474-86.

[11] Peterlin BL, Rosso AL, Sheftell FD, Libon DJ, Mossey JM, Merikangas KR. Post-traumatic stress disorder, drug abuse and migraine: new findings from the national comorbidity survey replication (NCS-R). Cephalalgia 2011;31:235-44.

[12] Saunders K, Merikangas K, Low NC, Von Korff M, Kessler RC. Impact of comorbidity on headache related disability. Neurology 2008;70:538-47.

[13] Maercker A, Michael T, Fehm L, Becker ES, Margraf J. Age of traumatization as a predictor of post-traumatic stress disorder or major depression in young women. $\mathrm{Br} \mathrm{J}$ Psychiatry 2004;184:482-7.

[14] Sareen J, Jacobi F, Cox BJ, Belik SL, Clara I, Stein MB. Disability and poor quality of life associated with comorbid anxiety disorders and physical conditions. Arch Intern Med 2006;166(19):2109-16.

[15] Radat F. Stress and migraine. Rev Neurol 2013;169(5):406-12.

[16] KRCT. Long-term sequels of war, social functioning and mental health in Kosovo (report). Kosova Rehabilitation Center for Torture Victims; 2006.
[17] Kashdan TB, Morina N, Priebe S. Post-traumatic stress disorder, social anxiety disorder, and depression in survivors of the Kosovo War: experiential avoidance as a contributor to distress and quality of life. J Anxiety Disord 2009;23:185-96.

[18] Ahern J, Galea S, Fernandez WG, Koci B, Waldman R, Vlahov D. Gender, social support, and posttraumatic stress in postwar Kosovo. J Nerv Ment Dis 2004;192:762-70.

[19] Cardozo BL, Kaiser R, Gotway CA, Agani F. Mental health, social functioning, and feelings of hatred and revenge of Kosovar Albanians one year after the war in Kosovo. J Trauma Stress 2003;16:351-60.

[20] Bidot S, Biotti D. Migraine with visual aura. J Fr Ophtalmol 2016;39(6):554-9.

[21] Kessler RC, Nelson B, McGonagle KA, Liu J, Swartz M, Blazer DG. Comorbidity of DSM III-R major depressive disorders from the US national comorbidity survey. Br J Psychiatry 1996;168(Suppl. 30):17-30.

[22] McDermott MJ, Fulwiler JC, Smitherman TA, Gratz KL, Connolly KM, Tull MT. The relation of PTSD symptoms to migraine and headache-related disability among substance dependent in patients. J Behav Med 2016;39(2):300-9.

[23] Buse DC, Silberstein SD, Manack AN, Papapetropoulos S, Lipton RB. Psychiatric comorbidities of episodic and chronic migraine. J Neurol 2013;260(8):1960-9.

[24] Morina N, Malek M, Nickerson A, Bryant RA. Psychological interventions for post-traumatic stress disorder and depression in young survivors of mass violence in low- and middle-income countries: meta-analysis. Br J Psychiatry 2017. pii:bjp.bp.115.180265.

[25] Niles AN, Dour HJ, Stanton AL, Roy-Byrne PP, Stein MB, Sullivan G, et al. Anxiety and depressive symptoms and medical illness among adults with anxiety disorders. J Psychosom Res 2015;78(2):109-15.

[26] Rao AS, Scher AI, Vieira RV, Merikangas KR, Metti AL, Peterlin BL. The impact of post-traumatic stress disorder on the burden of migraine: results from the national comorbidity survey-replication. Headache 2015;55 (10):1323-41. 